\title{
Correction to: Bacterial association observations in Lucilia sericata and Lucilia cuprina organs through 16S rRNA gene sequencing
}

\author{
N. E. Gasz ${ }^{1}$ - M. J. Geary ${ }^{2}$ - S. L. Doggett ${ }^{2}$ - M. L. Harvey ${ }^{1}$ \\ Published online: 9 March 2021 \\ (C) Springer-Verlag GmbH Germany, part of Springer Nature 2021
}

Correction to: Applied Microbiology and Biotechnology (2021) 105:1091-1106 https://doi.org/10.1007/s00253-020-11026-8

The published online version contains mistake in Figures 1 and 2. The researcher's regret that a publishing error has occurred in this article. Figure 1 was omitted and therefore does not appear in text. Figure 2 was also published missing key $\mathrm{x}$-axis information.

Figures 1 and 2 should appear as follows:

Publisher's note Springer Nature remains neutral with regard to jurisdictional claims in published maps and institutional affiliations.

The online version of the original article can be found at https://doi.org/ 10.1007/s00253-020-11026-8

N. E. Gasz

natalie.gasz@deakin.edu.au

1 School of Life and Environmental Sciences, Deakin University, Waurn Ponds Campus, 75 Pigdons Road, Locked Bag 20000, Geelong, VIC 3220, Australia

2 Department of Medical Entomology, NSW Health Pathology ICPMR, Westmead Hospital, Westmead, NSW 2145, Australia 
Total Bacterial Colony Abundance

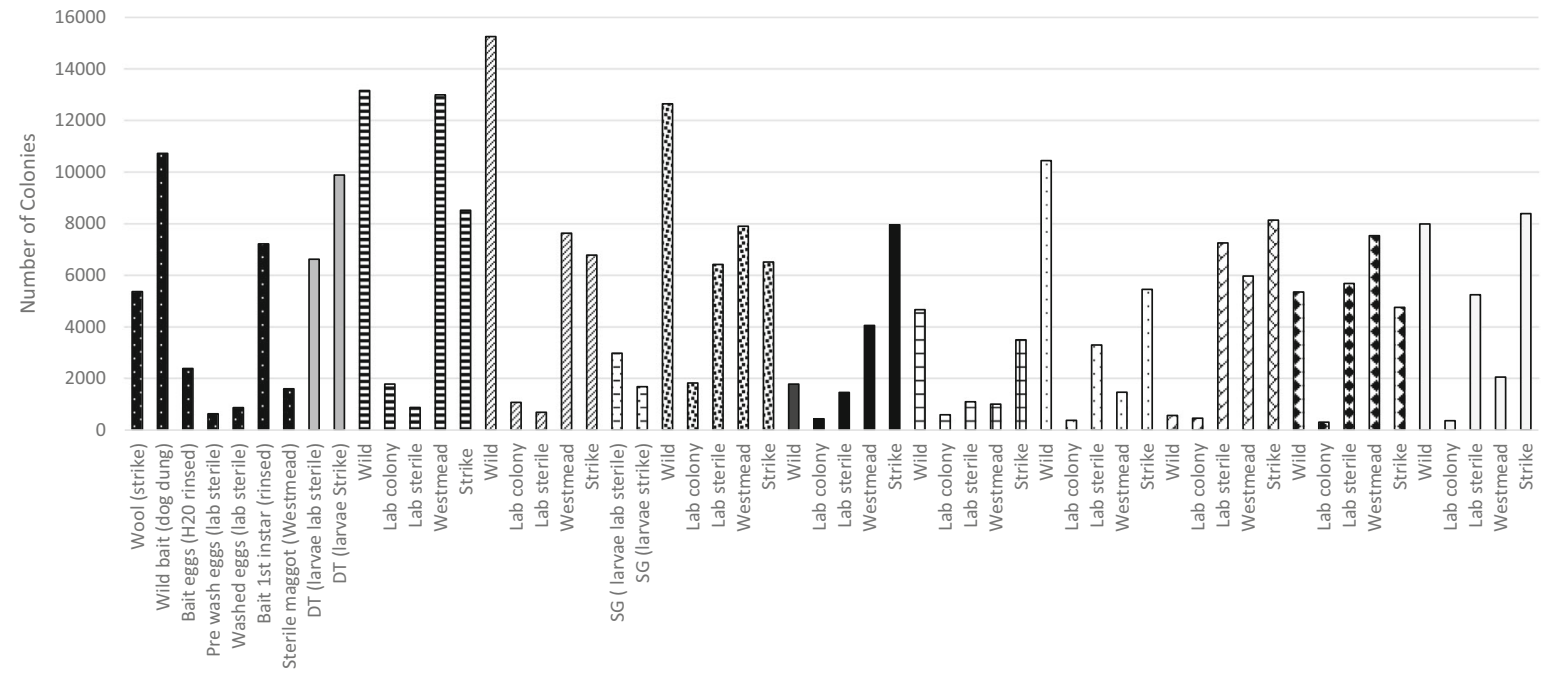

$\|$ Larval Digestive tract 自 Female Digestive Tract 目 Male Digestive Tract

H Spermatheca $\quad \forall$ Ovaries

Fig. 1 Total OTU count of bacterial sequences identified across all preliminary samples. Patterns denote organ sampled from specimens

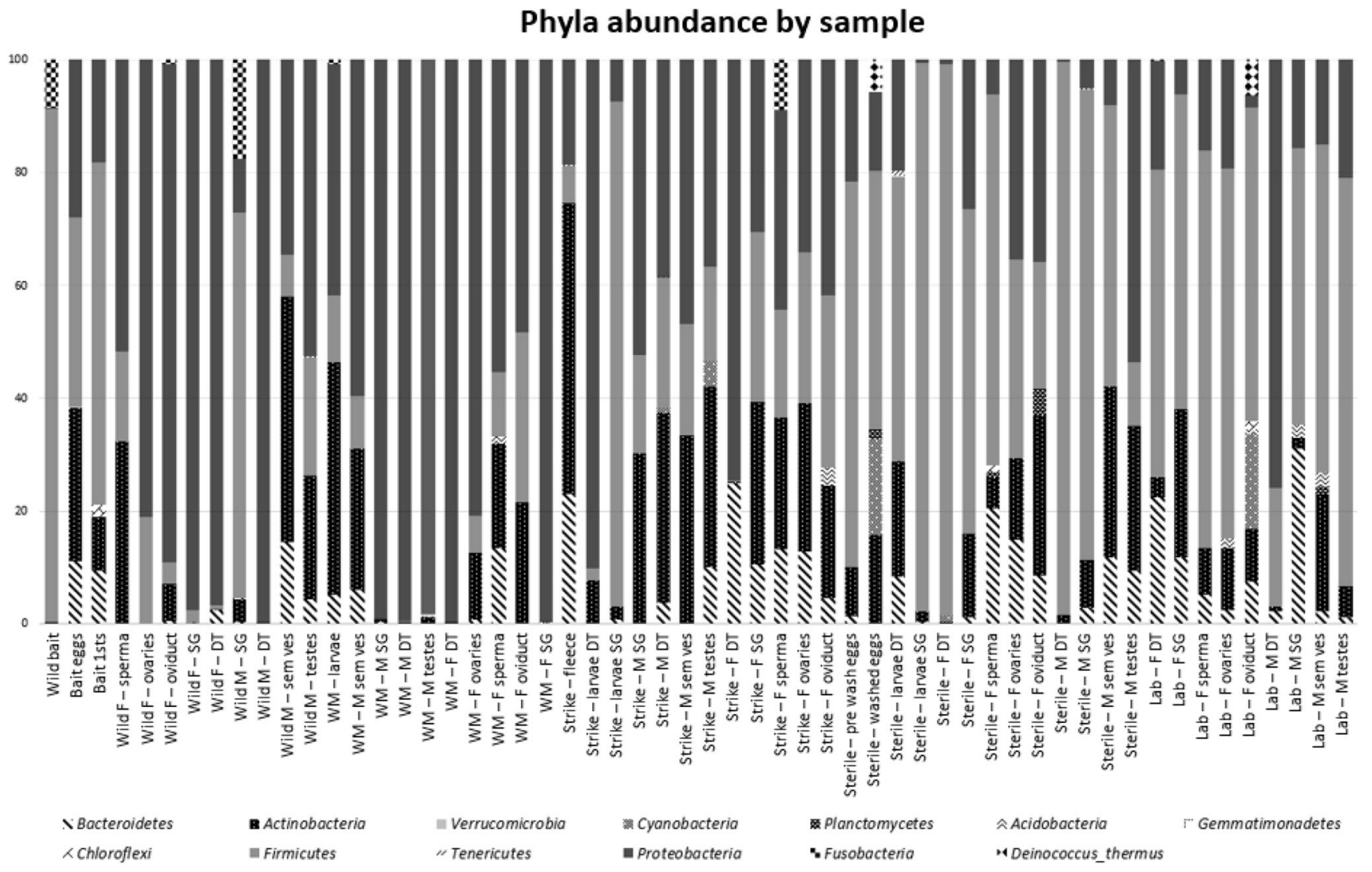

Fig. 2 Phyla diversity by sample through $16 \mathrm{~S}$ rDNA sequencing: $\mathrm{M}=$ male, $\mathrm{F}=$ female, $\mathrm{WM}=$ Westmead, $\mathrm{DT}=$ Digestive tract, $\mathrm{SG}=\mathrm{Salivary}$ gland, Ovar $=$ Ovaries, Sperma $=$ Spermatheca, Sem Ves $=$ Seminal vesicle 